\title{
Arte, conceitualismo e trotskismo no jornal argentino Política Obrera: o caso de censura e boicote ao Prêmio Braque em 1968 \\ Pedro Santana de Oliveira ${ }^{1}$ \\ DOI 10.20396/eha.vil4.3379
}

A década de 60 é um período de extrema efervescência de questões políticas e sociais que marcaram o Século XX e que vieram por sua vez influenciar as décadas seguintes. Com o fim da Segunda Guerra Mundial e início da Guerra Fria a política global acabou caindo num dualismo de ideias políticas que só foi ter fim após a queda do Muro de Berlim. De um lado, o Socialismo soviético dominando todo o leste europeu, além de apoiar regimes socialistas na Ásia, África e Caribe e, do outro lado, o Imperialismo norte-americano apoiando golpes de Estado em vários países a fim de evitar o avanço do socialismo e garantir apoio internacional.

Dentre os países latino-americanos que durante a década de 60 presenciaram o surgimento de ditaduras civil-militar está o caso da Argentina, que em 1966 sofreu com um golpe de Estado que acabou levando os militares ao poder. Com a ascensão de um governo ditatorial, muitos grupos políticos de viés socialista se formaram para fazer frente ao governo argentino e, dentre eles, está o jornal sindical Política Obrera fundado em 1964 e que posteriormente daria origem ao chamado Partido Obrero, um dos principais partidos de esquerda da Argentina de viés trotskista-leninista atuante até hoje.

Durante o período da ditadura militar argentina, o jornal Política Obrera se encarregou de publicar uma série de edições contra o regime, seja demonstrando apoio a greves de trabalhadores, seja repudiando atos de violência por parte do governo. Porém, dentre os artigos publicados nesse período, um deles se destaca: o artigo intitulado Rebelión de los artistas plásticos, publicado em 1968 referente ao boicote por parte dos artistas argentinos ao Prêmio Braque organizado pela embaixada francesa em Buenos Aires².

$\mathrm{O}$ artigo se destaca em meio as outras publicações do período por ser uma das poucas matérias publicadas pelo Política Obrera a tratar questões ligadas à arte. O conteúdo do artigo gira em

\footnotetext{
1 Estudante de Bacharelado em História da Arte (EBA/UFRJ). Atualmente interessasse por estudos em torno de temas como: História da arte, arte e política, expressões artísticas urbanas, cultura hip-hop e arte e questões raciais. Este trabalho foi desenvolvido com apoio do Programa de Bolsas de Iniciação Artística e Cultural da Universidade Federal do Rio de Janeiro, projeto Arte nas Américas: teorias e historiografias, sob orientação da profa. Patricia Corrêa (EBA/UFRJ).

2 REBELIÓN de los artistas plásticos, Politica Obrera, 1968, p. 27-31.
} 
torno da manifestação contrária ao Prêmio Braque, uma vez que, a organização da premiação dispunha de liberdade total para interferir diretamente nas obras dos artistas.

Além de ser uma nota de apoio aos artistas em questão, o artigo em si também evidencia muito do viés trotskista-leninista do jornal. Isso se deve ao fato de que em muitas partes do artigo são citados trechos do manifesto escrito por Leon Trotsky e André Breton em 1938, intitulado Manifesto por uma arte revolucionária independente. Neste manifesto, Trotsky e Breton criticam regimes políticos que tentam cooptar a arte e torná-la uma ferramenta de discurso político do Estado, além de reivindicarem total liberdade a arte.

No entanto, além de seu forte teor trotskista, o artigo também dialoga com um modo de se pensar arte que ganhou bastante destaque da década de 60 em diante, o chamado conceitualismo. Enquanto as três primeiras décadas do século XX foram marcadas pelas chamadas vanguardas europeias que, em suma, consistiram em movimentos artísticos em torno de questões culturais e estéticas opostas às tradições clássicas ou acadêmicas, a partir do segundo pós-guerra se identificam as chamadas neovanguardas, de forte teor conceitualista ${ }^{3}$. Estas se caracterizam pelo questionamento não somente com o fazer artístico, mas também com a própria instituição da arte, isto é, questiona todos os agentes e mecanismos que configuram a arte como um sistema (ensino, museus, crítica, mercado etc), logo questiona o próprio conceito de arte.

Nesse sentido, a autora Marília Andrés Ribeiro vai pontuar algumas questões que permeiam as chamadas vanguardas e neovanguardas na arte brasileira durante as décadas de 60/70. Ancorada nos pressupostos do poeta e ensaísta Augusto Campos, a autora vai colocar que:

"Campos mostra que as vanguardas das primeiras décadas do século XX criaram os pressupostos da linguagem artística da nossa época e que as neovanguardas, que surgiram na segunda metade do século XX, retomaram e desenvolveram as propostas das vanguardas históricas, dentro de um outro contexto, após a catástrofe das duas grandes guerras e a intervenção opressora dos regimes totalitários" ${ }^{4}$

O conceitualismo vai se colocar, portanto, não como um estilo, mas como um modo de pensar que colocaria em xeque os cânones de uma arte institucionalizada. Nesse sentido, a autora Mari Carmen Ramiréz descreve o conceitualismo, que teria surgido nos países europeus e nos Estados Unidos, como “É, antes, uma estratégia de antidiscursos cujas táticas evasivas põem em causa tanto a fetichização da arte como os sistemas de produção e distribuição de arte nas sociedades do capi- 
talismo tardio"s

Porém, para Ramiréz o conceitualismo na América Latina tomou rumos distintos quando comparados a contextos de países desenvolvidos. Isso se deve ao fato de que o conceitualismo se manifestou na América Latina durante esse período de extrema repressão política por parte dos governos locais, o que fez com que a arte conceitual latino-americana desenvolvesse um teor político muito mais evidente do que nos demais países cujos artistas também experimentaram o conceitualismo.

Portanto, o texto do jornal Política Obrera, começa tratando do boicote ao Prêmio Braque de 1968 como "un episodio de un proceso de politizacion que en los últimos meses abarca a muchos artistas plásticos"6, visto que um dos estopins do boicote foi a censura da legenda de uma obra contendo uma crítica ao presidente militar argentino da época, Juan Carlos Onganía. No entanto, o texto se desenrola apontando outras críticas que podemos associar à postura conceitualista da época, atreladas aos ideais de viés marxista do jornal, uma vez que, o artigo vai se pontuar que o contexto externo da rebelião é um contexto de crise política da arte.

Esse pensamento se reflete, por exemplo, na parte inicial do artigo em que os prêmios e as mostras de arte são definidos como espaços de domesticação das tendências artísticas, onde o artista é obrigado a atender aos gostos de uma burguesia e tem sua qualidade medida no valor de suas obras. Nesse ponto, o jornal demonstra uma convergência com o pensamento conceitualista, na medida em que visa questionar as instituições artísticas bem como os seus espaços legitimadores e a fetichização da arte, que no contexto do jornal dialoga com a ideia do fetiche das mercadorias proposta por Karl Marx.

A crítica institucional se sucede no texto com o levantamento do contexto político da época. Escrito em 1968, o artigo foi publicado num momento marcado por grandes protestos de cunho social e político, dos quais os mais emblemáticos foram os protestos de maio de 1968 na França, que culminaram por afetar o que o texto coloca como o "maior mercado de arte do mundo" Veneza.

Além do viés de crítica institucional, como dito anteriormente o artigo traz em seu decorrer algumas passagens do manifesto artístico escrito por Trotsky e Breton, o Manifesto por uma arte revolucionária independente, que critica um contexto de cooptação da arte que vai encontrar ressonância

\footnotetext{
5 RAMIREZ, 2007, p. 185.

6 REBELIÓN de los artistas plásticos, 1968, p. 27.

7 REBELIÓN de los artistas plásticos, 1968, p.28
} 
no boicote ao Prêmio Braque. Ao escrevê-lo em 1938, Trotsky e Breton criticavam os regimes stalinista e hitlerista na União Soviética e na Alemanha, respectivamente, por serem regimes que visavam controlar a arte para fins políticos e sob a tutela do estado.

Segundo Trotsky, a arte deveria se desenvolver sobre as suas leis, e que não deveria haver qualquer ato de coação por parte do Estado sobre a produção intelectual e artística, portanto, o autor vai colocar no manifesto que:

"Se, para o desenvolvimento das forças produtivas materiais, cabe à revolução erigir um regime socialista de plano centralizado, para a criação intelectual ela deve, já desde o começo, estabelecer e assegurar um regime anarquista de liberdade individual. Nenhuma autoridade, nenhuma coação, nem o menor traço de comando!"8

Dito isso, o artigo do Política Obrera vai se utilizar do manifesto escrito por Trotsky e Breton para tecer críticas não somente a instituição artística que visava cooptar as obras dos artistas, como também criticar o regime capitalista que visava transformar as obras de arte em meras mercadorias para agradar um gosto burguês.

No entanto, o artigo também se encarrega de traçar críticas a uma outra vertente do trotskismo internacional, o chamado posadismo. Idealizado por Juan R. Posadas, o posadismo possuía uma visão diferente acerca da arte quando comparada com o pensamento do jornal Política Obrera. Segundo os posadistas, a arte é fruto da luta de classes e se configura como uma expressão de um pensamento pequeno burguês e que, portanto, acabaria com a ascensão do comunismo. Desse modo, o artigo do jornal vai se desenrolar rebatendo esse pensamento posadista afirmando que para haver uma revolução socialista é preciso ter uma organização social, mas que o artista pode ser um revolucionário e ter liberdade expressiva, diferentemente do posadismo que afirmava que para um artista ser um revolucionário precisaria abdicar do fazer artístico.

Na parte final do artigo, o jornal vai se embasar novamente no manifesto de Trotsky para defender a liberdade total no fazer artístico. No entanto, o Política Obrera vai pontuar que isso não significa justificar uma arte apolítica ou dissociada da vida como um todo, uma vez que o próprio artigo reconhece como algo impossíve ${ }^{10}$. Ao invés disso, o jornal vai pontuar a importância da arte como instrumento de conscientização social e como uma ferramenta de luta contra o imperialismo e as opressões.

\footnotetext{
8 TROTSKY, 1938, p. 42.

9 REBELIÓN de los artistas plásticos, 1968, p. 29.

10 REBELIÓN de los artistas plásticos, 1968, p. 30.
} 
Dito isso, oartigo do PolíticaObrera, evidencia em sua totalidade o quesignificou o pensamento trotskista em torno da arte no século XX. Diferentemente de outras ideologias de viés marxista, o trotskismo se configurou talvez como o modo pensar a arte livre de cânones institucionais e de amarras do sistema capitalismo que estariam impregnadas nas academias, bienais, mostras e leilões.

Diferentemente do regime stalinista na União Soviética (URSS) que impunha um estilo artístico oficial, o chamado realismo soviético, o trotskismo propunha uma não cooptação da arte, independentemente da instituição, e dessa forma, adiantando um pensamento que ganhou mais força com arte conceitual contemporânea. Não à toa, os pensamentos de Leon Trotsky e André Breton viriam a influenciar muitos críticos e teóricos da arte moderna e contemporânea, dentre eles Clement Greenberg e Mario Pedrosa.

Referências bibliográficas

BRETON, André; RIVERA, Diego. ¡Por un arte revolucionario independiente! In: Arte y política, editado por Raquel Tibol, p. 181-186. Cidade do México, 1979.

FREITAS, Artur. “Arte conceitual e Conceitualismo: uma síntese teórica.” In: Concinnitas n. 18, Junho de 2011.

GIORGI, Guido Ignacio. Redes católicas e Estado na "Revolução Argentina" In: CSOnline-Revista Eletrônica de Ciências Sociais, ano 4, ed. 11, set./dez. 2010.

RAMÍREZ, Mari Carmen. Táticas para viver da Adversidade. O conceitualismo na América Latina. Arte\&Ensaios. Rio de Janeiro, ano XIV, n. 15, 2007.

REBELIÓN de los artistas plásticos. Política Obrera., Buenos Aires. v. 3, n. 34, p. 27-31, agosto. 1968.

RIBEIRO, Marília Andrés. "Reflexão sobre a arte brasileira nos anos de 1960/70." In: Revista Porto Arte: Porto Alegre, n. 19, n. 33, novembro/2012. 